\title{
Armed Conflict in Central America and Immigrant Food Insecurity in the United States
}

\author{
Jeremy C. Green ${ }^{1, *}$, Eric Adjei Boakye ${ }^{2}$, Ellen K. Barnidge ${ }^{3}$, Michael G. Vaughn ${ }^{4}$ \\ ${ }^{1}$ Saint Louis University, Department of Health Management and Policy, Saint Louis, MO, USA \\ ${ }^{2}$ Southern Illinois University School of Medicine, Department of Population Science and Policy, Springfield, MO, USA \\ ${ }^{3}$ Saint Louis University, Department of Health Behavior and Education, Saint Louis, MO, USA \\ ${ }^{4}$ Saint Louis University, School of Social Work, Saint Louis, MO, USA
}

\section{ARTICLE INFO}

\section{Article History}

Received 5 January 2018

Accepted 28 February 2018

Keywords

Armed conflict

food supply

immigrant

\begin{abstract}
Central American immigrants to the United States are a growing population with rates of food insecurity that exceed national averages. We analyzed multiple years of data from the Center for System Peace and the Current Population Survey, Food Security Survey Module, from 1998 to 2015. We used ordered probit and probit regressions to quantify associations between premigration residence in a country exposed to armed conflict in Central America and the food insecurity of immigrants in the United States. The study sample included 5682 females and 5801 males between the ages of 19 and 69 years who were born in Central America and migrated to the United States. The mean age of individuals included in the study sample was 38.2 years for females (standard deviation, 11.0) and 36.8 years for males (standard deviation, 10.6). Premigration armed conflict was associated with a $10.7 \%$ point increase in postmigration food insecurity among females (95\% confidence interval, $6.8-14.5$ ), and a 9.5\% point increase among males (95\% confidence interval, 5.0-14.0).
\end{abstract}

(c) 2018 Atlantis Press International B.V. This is an open access article under the CC BY-NC license (http://creativecommons.org/licenses/by-nc/4.0/).

\section{INTRODUCTION}

Central American immigrants to the United States are a growing population [1-3] with rates of food insecurity higher than national averages [2,3]. Studies of food insecurity in this population are increasingly important as immigrants suffer deteriorating economic and social conditions [4]. The migration experience can be associated with changes in the food environment [5]. Food insecurity among immigrant populations in the United States can be related to lack of education [5-7] and income [2,6], as well as the need to help provide for family members in countries of origin [6]. Some individuals migrate in order to escape harmful premigration conditions in immigrant countries of origin including food insecurity [8]. Previous research examining food security among immigrant populations in the United States include studies in California $[2,7,9,10]$, Iowa [2], Massachusetts [5,7,11], Michigan [2], North Carolina [6], Oregon [2], and others [7,12]. The impact of premigration experiences in immigrant countries of origin on food security, however, is not as well documented in this population [13]. Some studies of food insecurity do include data relating to countries and regions of origin $[7,10,11]$. However, these studies do not include data that describes variation in characteristics of the premigration environments of countries and regions of origins.

In this paper, we study postmigration food insecurity in the United States and its associations with premigration residence in a country exposed to armed conflict in Central America. Armed conflict can

*Corresponding author. Email: jeremy.green@slu.edu have deleterious consequences for food security and nutrition for many reasons [14]. Conflict and postconflict communities can suffer destruction of natural resources, loss of land, and volatility of food prices that can have important consequences for the food security of populations [15]. Armed conflict can also result in the loss of access to healthcare services and the onset of poverty that can have consequences for decades. Food insecurity can also be related to changes in political stability that result from armed conflict [16] and farmland can be destroyed for political and strategic reasons [17]. Armed conflict can also result in malnutrition and disease [18]. Research on the population health effects of armed conflict is limited by a focus on its short-term effects [19], and few studies examine associations between armed conflict and food insecurity [20]. Armed conflict often leads to long-term food shortages, and can interact with economic and environmental problems to generate more damage [21].

Nutrition shortages are often a social cost of violence, and deserve more research attention in the global and public health literatures. We combined multiple sources of data to quantify associations between premigration residence in a country exposed to armed conflict and postmigration food insecurity, educational attainment, and household income. Our research aims to expand the literature on food insecurity for immigrant populations, by incorporating data on the premigration experiences of immigrant countries of origin into the analysis of postmigration outcomes. Results from our analysis contribute empirical evidence to conceptual frameworks that take a life course approach to immigrant outcomes, and to the social science literature on associations between early life events and adult outcomes. 


\section{MATERIALS AND METHODS}

We combined country by year level data on premigration armed conflicts in Central America with individual level data on postmigration food security, education, and income in the United States to quantify associations between premigration armed conflict and postmigration food security, education, and income. We used three measures of premigration armed conflict-any premigration armed conflict, years of premigration armed conflict, and years since most recent premigration armed conflict-to test for cumulative associations between premigration armed conflict and postmigration outcomes, and to ascertain the extent to which the associations might fade over time. The follow sections describe the data sources, the study variables, and the statistical methods.

\subsection{Data Sources}

To measure postmigration household-level food security, we analyzed data from the United States Food Security Survey Module collected as part of the Current Population Survey, Food Security Supplement, from 1998 to 2015 [22]. The Food Security Supplement data are collected annually, each December, by the United States Department of Agriculture, Economic Research Service and Food and Nutrition Service. The United States Food Security Survey Module was designed by the United States Department of Agriculture, to facilitate research on households with limited or uncertain access to food due to economic reasons. Studies of the United States Food Security Survey Module in immigrant populations found the module to be robust to different levels of acculturation [23] and consistent with related surveys [24,25]. We included for the study sample those individuals in the Food Security Supplement data who were aged 19-69 years at the time of the survey, born in Central America, and currently living in the United States. To measure premigration armed conflict, we analyzed data from the Center for Systemic Peace, Integrated Network for Societal Conflict Research, Major Episodes of Political Violence file, from 1948 to 2015 [26]. The Major Episodes of Political Violence file contains country by year level data on armed conflicts throughout this time period.

\subsection{Dependent Variables}

We evaluated three outcomes of interest in the Food Security Supplement microdata: household food security, survey respondent education, and household income. Household food security was defined using the three categories from the United States Food Security Survey Module. The three categories of food security were: (1) food security; (2) low food security; and (3) very low food security. Survey respondent education was derived from the educational attainment variable, which indicates the highest grade in school or year of college completed by each of the survey respondents. We used this educational attainment variable to create a dichotomous variable for whether each survey respondent graduated high school by the time of the survey. Household income was defined using the dichotomous variable from the Food Security Supplement data. This variable classifies each household as having an income $>185 \%$ or $<185 \%$ of the federal poverty level.

\subsection{Independent Variables}

We created three measures of premigration armed conflict-any premigration armed conflict, years of premigration armed conflict, and years since premigration armed conflict-by coding the country by year level data on armed conflicts from the Major Episodes of Political Violence file into the life course of each individual in the study sample from the Food Security Supplement microdata. To quantify any premigration armed conflict, we classified each individual as either exposed or not exposed to premigration armed conflict, by creating an indicator for each individual that was born in a country with an armed conflict during or after their year of birth and before or during their year of migration to the United States, using the year of immigration variable in the study dataset. To quantify years of premigration armed conflict, we computed the sum of the number of armed conflicts that occurred in each individual's country of birth after they were born and before they migrated. To quantify years since premigration armed conflict, we subtracted the year of the most recent premigration armed conflict during or after an individual's year of birth and before or during their year of migration to the United States, from the year that the individual completed the Food Security Supplement survey.

\subsection{Statistical Analysis}

The statistical analysis proceeded in three steps: (1) we described our data on each of the premigration armed conflict variables; (2) we examined the distribution of the food security, education, and income outcomes by premigration armed conflict; and (3) we used multivariable regressions to estimate age-adjusted associations between each of the three premigration armed conflict variables and each of the postmigration outcome distributions.

To describe our data on each of the premigration armed conflict variables, we examined the prevalence of premigration armed conflict in the study sample, and the duration of premigration armed conflict in the study sample. For survey respondents with at least 1 year of premigration armed conflict, we also examined the time since premigration armed conflict in the study sample. We described the distribution of each premigration armed conflict variable by country of birth, and by sex. For the dichotomous variable for any premigration armed conflict, we reported counts and frequencies by country of birth and sex. For the continuous variables for years of premigration armed conflict and years since premigration armed conflict, we reported means and standard deviations by country of birth and sex. To describe the postmigration outcomes in relation to premigration armed conflict, we prepared a figure that depicts each of the outcome distributions, for survey respondents who did and did not reside in a country exposed to premigration armed conflict during or after their year of birth and before or during their year of migration from Central America to the United States.

To quantify age-adjusted associations between premigration exposure to armed conflict and postmigration outcomes using regression analysis, we fitted nonlinear regression models of the postmigration outcome distributions on each of the premigration armed conflict variables. For the food security outcome, we included each of the three categories of food security 
outcome-food security, low food security, and very low food security-by fitting multivariate ordered probit regressions. We estimated associations between premigration armed conflict and the dichotomous postmigration education and income outcomes by fitting probit regressions. After fitting each regression, we used the regression coefficients to generate predictions of the association between premigration armed conflict and each postmigration outcome. For the dichotomous premigration armed conflict variable for any armed conflict, we predicted the incremental effect of armed conflict on the outcomes [27]. For the continuous premigration armed conflict variables for years of armed conflict and years since armed conflict, we predicted the average marginal effect of armed conflict on the outcomes [28].

To facilitate interpretation of results from regression analyses, we divided the number of years of premigration armed conflict, and the number of years since premigration armed conflict, by 10 before fitting the regressions. This resulted in key independent variables for the number of decades of premigration armed conflict, and the number of decades since premigration armed conflict. For each of the regressions, covariates were included for age, age-squared, and age-cubed to condition the associations on the age distributions observed in the study sample. Confidence intervals were computed from delta method standard errors [29]. We incorporated the design of survey using the survey sampling weights in regression analyses. We used Stata software version 14, manufactured by StataCorp in College Station, TX, USA to create and analyze the dataset [30]. Hypothesis tests were two tailed and statistical significance was set at $p<0.05$. Sex was entered into the data analysis by stratifying the results by a dichotomous indicator for female or male sex.

\section{RESULTS}

The study sample included survey respondents between the ages of 19 and 69 years at the time of the health outcomes survey. In Tables 1-6 we report the results of the descriptive and inferential statistical analyses. Tables 1-3 contain the results of the descriptive analyses, and Tables 4-6 contain the results of the inferential analyses.

Counts and frequencies of survey respondents with premigration residence in a country exposed to armed conflict are reported in Table 1. The first column of the table reports the counts and

Table 1 Premigration armed conflict for Central American immigrants

\begin{tabular}{lcc}
\hline \multirow{2}{*}{ Country of birth } & \multicolumn{2}{c}{ Premigration armed conflict, No. $(\%)^{\mathrm{a}}$} \\
\cline { 2 - 3 } & Females $(\boldsymbol{n}=\mathbf{5 6 8 2})$ & Males $(\boldsymbol{n}=\mathbf{5 8 0 1})$ \\
\hline Belize & 0 & 0 \\
Costa Rica & $30(17.1)$ & $27(18.0)$ \\
El Salvador & $2503(98.0)$ & $2434(98.4)$ \\
Guatemala & $1217(99.8)$ & $1643(100.0)$ \\
Honduras & $848(96.8)$ & $837(98.0)$ \\
Nicaragua & $447(97.4)$ & $405(97.6)$ \\
Panama & $116(40.7)$ & $54(26.9)$ \\
Total & $5161(90.8)$ & $5400(93.1)$ \\
\hline
\end{tabular}

${ }^{a}$ Table entries are counts and frequencies of premigration armed conflict. For each individual, premigration armed conflict includes any armed conflict that occurred during or after their year of birth, and before or during their year of migration to the United States.
Table 2 Years of premigration armed conflict for Central American immigrants

\begin{tabular}{lcc}
\hline \multirow{2}{*}{ Country of birth } & \multicolumn{2}{c}{ Years of premigration armed conflict, mean $(\mathrm{SD})^{\mathrm{a}}$} \\
\cline { 2 - 3 } & Females $(\boldsymbol{n}=\mathbf{5 6 8 2})$ & Males $(\boldsymbol{n}=\mathbf{5 8 0 1})$ \\
\hline Belize & 0 & 0 \\
Costa Rica & $0.216(0.512)$ & $0.227(0.520)$ \\
El Salvador & $9.793(4.769)$ & $10.02(4.616)$ \\
Guatemala & $18.40(7.390)$ & $18.12(7.131)$ \\
Honduras & $14.21(6.952)$ & $14.81(6.563)$ \\
Nicaragua & $8.412(3.919)$ & $8.537(3.786)$ \\
Panama & $0.407(0.492)$ & $0.269(0.444)$ \\
Total & $11.25(7.532)$ & $12.21(7.420)$ \\
\hline
\end{tabular}

${ }^{a}$ Table entries are means and standard deviations for the number of years of premigration armed conflict. For each individual, the number of years of premigration armed conflict includes years of armed conflict that occurred in their country of birth, during or after their year of birth, and before or during their year of immigration to the United States; SD, standard deviation.

Table 3 Years since premigration armed conflict for Central American immigrants

\begin{tabular}{lcc}
\hline $\begin{array}{l}\text { Country of } \\
\text { birth }\end{array}$ & Years since last premigration armed conflict, mean $(\mathrm{SD})^{\mathrm{a}}$ \\
\cline { 2 - 3 } & Females $(\boldsymbol{n}=\mathbf{5 1 6 1})$ & Males $(\boldsymbol{n}=\mathbf{5 4 0 0})$ \\
\hline Belize & $\mathrm{N}^{\mathrm{b}} \mathrm{A}^{\mathrm{b}}$ & $\mathrm{N}^{\mathrm{b}}$ \\
Costa Rica & $52.13(5.043)$ & $50.52(4.467)$ \\
El Salvador & $18.96(6.676)$ & $18.50(6.423)$ \\
Guatemala & $17.48(7.876)$ & $16.11(7.194)$ \\
Honduras & $20.01(6.840)$ & $18.38(5.415)$ \\
Nicaragua & $20.39(8.093)$ & $19.58(7.347)$ \\
Panama & $19.27(4.687)$ & $19.17(4.567)$ \\
Total & $19.11(7.580)$ & $18.00(7.066)$ \\
\hline
\end{tabular}

${ }^{a}$ Table entries are means and standard deviations for the number of years since the last premigration armed conflict. For each individual, the last premigration armed conflict occurred in their country of birth, during or after their year of birth, and before or during migration; ${ }^{\mathrm{b}}$ There were no armed conflicts in Belize during the study period; N/A, not applicable; SD, standard deviation.

Table $4 \mid$ Premigration armed conflict and Central American immigrant outcomes

\begin{tabular}{lcc}
\hline \multirow{2}{*}{ Outcome } & \multicolumn{2}{c}{ Incremental effect $^{\mathrm{a}}\left(\mathbf{9 5 \%} \mathbf{C I}^{\mathrm{b}}\right)^{\mathrm{c}}$} \\
\cline { 2 - 3 } & \multicolumn{1}{c}{ Females $(\boldsymbol{n}=\mathbf{5 6 8 2})$} & Males $(\boldsymbol{n}=\mathbf{5 8 0 1})$ \\
\hline Food security $^{\mathrm{d}}$ & $-0.107[-0.145,-0.0678]$ & $-0.0951[-0.140,-0.0499]$ \\
Education $^{\mathrm{d}}$ & $-0.344[-0.381,-0.307]$ & $-0.361[-0.403,-0.318]$ \\
Income $^{\mathrm{e}}$ & $-0.217[-0.263,-0.171]$ & $-0.240[-0.290,-0.190]$ \\
\hline
\end{tabular}

ancremental effects on food security are from ordered probit regressions of the outcome distributions on premigration armed conflict. Incremental effects on education and income are from probit regressions of education and income on premigration armed conflict; ${ }^{\text {b }} 95 \%$ CI were computed using the delta method; ${ }^{c}$ Table entries are incremental effects and 95\% CI for the associations between premigration armed conflict and postmigration outcomes. For each individual, premigration armed conflict includes any armed conflict that occurred in their country of birth, during or after their year of birth, and before or during their year of immigration to the United States. Incremental effects and 95\% CI are estimated using sample weights. Estimates are adjusted for the observed distributions of cubic age trends; ${ }^{\mathrm{d} S u r v e y}$ respondent graduated from high school; ${ }^{\mathrm{e} H o u s e h o l d ~ i n c o m e ~ i s ~}>185 \%$ of the federal poverty level; CI, confidence interval.

frequencies for females. The second column of the table reports the counts and frequencies for males. We defined premigration residence in a country exposed to armed conflict to include those armed conflicts that occurred in a survey respondent's country of 
Table 5 Decades of premigration armed conflict and Central American immigrant outcomes

\begin{tabular}{lcc}
\hline \multirow{2}{*}{ Outcome } & \multicolumn{2}{c}{ Average marginal effect ${ }^{\mathrm{a}}\left(\mathbf{9 5 \%} \mathbf{C I}^{\mathrm{b}}\right)^{\mathrm{c}}$} \\
\cline { 2 - 3 } & Females $(\boldsymbol{n}=\mathbf{5 6 8 2})$ & Males $(\boldsymbol{n}=\mathbf{5 8 0 1})$ \\
\hline Food security $^{\mathrm{d}}$ & $-0.0562[-0.0731,-0.0394]$ & $-0.0372[-0.0536,-0.0208]$ \\
Education $^{\mathrm{d}}$ & $-0.144[-0.162,-0.125]$ & $-0.159[-0.178,-0.140]$ \\
Income $^{\mathrm{e}}$ & $-0.0970[-0.117,-0.0774]$ & $-0.101[-0.121,-0.0817]$ \\
\hline
\end{tabular}

aAverage marginal effects are from ordered probit regressions of the distribution of outcome distributions on the number of decades of premigration armed conflict; ${ }^{b} 95 \%$ CI were computed using the delta method; 'Table entries are average marginal effects and $95 \% \mathrm{CI}$ for the associations between the number of decades of premigration armed conflict and postmigration outcomes. For each individual, the number of decades of premigration armed conflict includes armed conflicts that occurred in their country of birth, during or after their year of birth, and before or during their year of immigration to the United States. Average marginal effects and $95 \% \mathrm{CI}$ are estimated using sample weights. Estimates are adjusted for the observed distributions of cubic age trends; ${ }^{\mathrm{A} S u r}-$

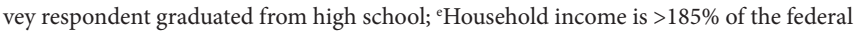
poverty level; $\mathrm{CI}$, confidence interval.

Table 6 Decades since premigration armed conflict and Central American immigrant outcomes

\begin{tabular}{lcc}
\hline \multirow{2}{*}{ Outcome } & \multicolumn{2}{c}{ Average marginal effect $^{\mathrm{a}}\left(\mathbf{9 5 \%} \mathbf{C I}^{\mathrm{b}}\right)^{\mathrm{c}}$} \\
\cline { 2 - 3 } & Females $(\boldsymbol{n}=\mathbf{5 1 6 1})$ & Males $(\boldsymbol{n}=\mathbf{5 4 0 0})$ \\
\hline Food security $^{\mathrm{d}}$ & $0.0398[0.0179,0.0616]$ & $0.0349[0.0136,0.0561]$ \\
Education $^{\mathrm{d}}$ & $0.129[0.106,0.152]$ & $0.134[0.110,0.159]$ \\
Income $^{\mathrm{e}}$ & $0.0678[0.0445,0.0911]$ & $0.0870[0.0624,0.112]$ \\
\hline
\end{tabular}

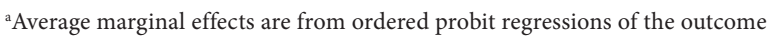
distributions on the number of decades since premigration armed conflict; ${ }^{\text {b }} 95 \% \mathrm{CI}$ were computed using the delta method; 'Table entries are average marginal effects and $95 \% \mathrm{CI}$ for the associations between the number of decades since the last premigration armed conflict and postmigration outcomes. For each individual, the last premigration armed conflict occurred in their country of birth, during or after their year of birth, and before or during their year of immigration to the United States. Average marginal effects and 95\% CI are estimated using sample weights. Estimates are adjusted for the observed distributions of cubic age trends. ${ }^{\text {SSurvey respondent }}$

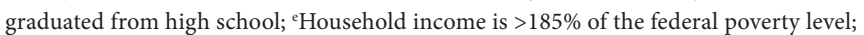
CI, confidence interval.

birth during or after their year of birth, and before or during their year of immigration to the United States. The study sample included individuals between the ages of 19 and 69 years at the time of the Food Security Supplement of the Current Population Survey. Belize experienced no premigration armed conflict, whereas Guatemala experienced the highest rates of premigration armed conflict.

Table 2 reports the means and standard deviations for the number of years of premigration residence in a country exposed to armed conflict among individuals responding to the Food Security Supplement of the Current Population Survey. The first column of this table reports the results for females. Belize experienced no years of premigration armed conflict, whereas Guatemala experienced the most years of premigration armed conflict. The second column of this table reports the results for males. Table 3 reports the means and standard deviations for the number of years since the most recent year of premigration residence in a country exposed to armed conflict among the subgroup of individuals with at least 1 year of premigration residence in a country exposed to armed conflict. Among the subgroup of respondents with at least 1 year of premigration residence in a country exposed to armed conflict, individuals from Guatemala had the most recent year of premigration residence during armed conflict, and individuals from Costa Rica had the least recent year of premigration residence during armed conflict. In Figure 1, we provide the results of our descriptive analysis that relates the postmigration distributions of food security, educational attainment, and household income to premigration armed conflict.

We report the results of the inferential statistical analyses in Tables 4-6. In Table 4, we report the age-adjusted associations between premigration residence in a country exposed to armed conflict, and each of the outcomes. In age-adjusted analyses for females and males, we found statistically significant, negative associations between premigration residence in a country exposed to armed conflict and postmigration household food insecurity, educational attainment, and household income. In Table 5, we report the age-adjusted associations between the number of decades of premigration residence in a country exposed to armed conflict, and each of the outcomes. These results show that the associations between premigration residence in a country exposed to armed conflict and postmigration outcomes are cumulative, as the duration of premigration residence in a country exposed to armed conflict is associated with each of the postmigration outcomes. In Table 6, we report the age-adjusted associations between the number of decades since the most recent premigration armed conflict exposure, and each of the outcomes. We found that the associations between premigration residence in a country exposed to armed conflict and postmigration outcomes fade over time, for both females and males.

\section{DISCUSSION}

Our study found that premigration residence in a country exposed to armed conflict is associated with postmigration food insecurity in a nationally representative sample of Central American immigrants to the United States. Our results expand the literature

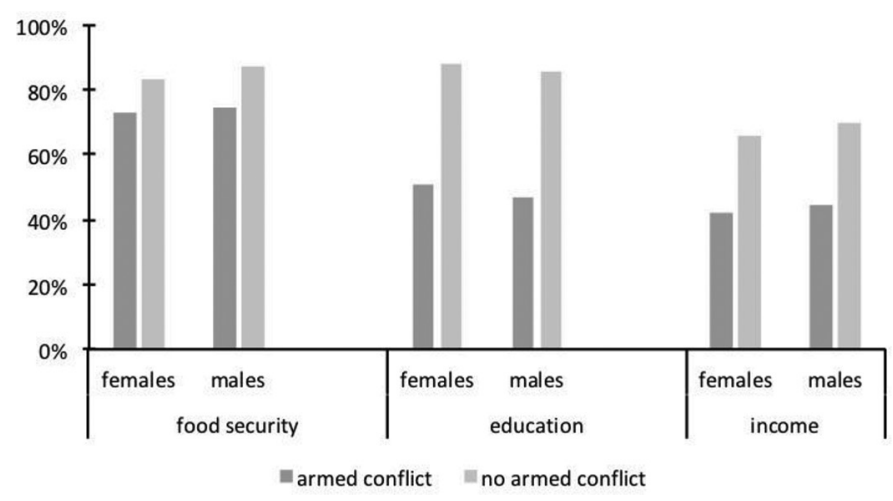

Figure 1 The postmigration distributions of food security, education, and income in the United States, by premigration armed conflict in Central America. Food security is defined by the food security survey module, designed by the United States Department of Agriculture. Educational attainment is high school graduation. Household income is $>185 \%$ of the United States federal poverty level. The United States federal poverty level, defined annually by the number of children in the household, is designed by the United States Department of Health and Human Services. Premigration armed conflict includes those individuals who lived in a country exposed to armed conflict during or after their year of birth and before or during their year of migration 
on associations between armed conflict and food insecurity, by examining premigration residence in a country exposed to armed conflict, and postmigration food insecurity. Maxwell et al. [21] used cross-national data between 1996 and 2010 to quantify associations between the duration of protracted crises including armed conflict with undernourishment and hunger. The authors found statistically significant associations between the number of years of crisis and the prevalence of undernourishment and hunger, after adjusting their estimated associations between crises and food insecurity for variation in income, education, government effectiveness, and the control of corruption. Our findings extend the results of Maxwell et al. [21] to test the novel hypothesis that these associations can persist for at least 20 years in displaced populations, even after they migrated away from a crisis.

Results from our study suggest that variables relating to premigration residence in a country exposed to armed conflict should be included in studies of food insecurity in immigrant populations in the United States and other receiving countries. Allouche [16] describes the literature relating armed conflict and food insecurity as more typically limited to conflict settings rather than postconflict settings while suggesting that effects of armed conflict on food insecurity might be pronounced in displaced populations. Chilton et al. [7] analyzed data collected from 1998 to 2005 from 19,275 mothers including 7216 immigrant mothers in seven cities within the United States and found statistically significant associations between food insecurity and child health in immigrant populations. Our results suggest that this analysis might be expanded by including premigration armed conflict as a predictor of food insecurity in displaced populations and their offspring. Devakumar et al. [17] describes the many studies on intergenerational health effects of armed conflict including obstetric complications, maternal mortality, neonatal mortality, low birth weight, and impaired child growth and development.

Researchers can use our results to expand on this literature, and explore the possibility of intergenerational, transnational effects of premigration armed conflict on the prevalence of postmigration food insecurity in displaced populations in relation to the nutritional status of their offspring. Researchers can also use our results to expand existing conceptual frameworks of food insecurity in immigrant populations. Sano et al. [2] describe different levels of ecological systems that contribute to immigrant food insecurity within their postmigration environment. Their conceptual framework could be expanded to include the lingering effects of premigration ecological systems on postmigration food insecurity.

Evidence on these and other previously undocumented effects of armed conflicts have the potential to help inform political and policy debates surrounding food insecurity in relation to the onset of conflicts and recovery in their aftermath. Koren and Bagozzi [20] describe the tendency of policies that intend to alleviate the problem of food insecurity to focus myopically on the dietary and nutritional antecedents of food insecurity, while neglecting the potential role of political violence in relation to food insecurity. Similarly, in their review and synthesis of the literatures relating to armed conflict and food insecurity, Messer and Cohen [15] identify several opportunities to better integrate agricultural and nutritional planning with conflict alleviation and peacebuilding efforts. For example, they suggested breaking down silos between nutrition and peacebuilding units of international nongovernmental organizations, and increasing attention to political conflict by the World Bank. These recommendations are consistent with the views of Allouche [16] who suggests that food insecurity is driven more by political conflict and less by natural resource constraints than might be suggested by the focus of some contemporary organizations and policies. As described by Maltz [14], relationships between armed conflict and food insecurity can be found in studies of World War I and II, and studies of these historical relationships can help to guide contemporary policy by encouraging increased, transnational collaboration between local, national, and international organizations concerned with food insecurity.

Our study results should be interpreted in light of several known caveats of our dataset: (1) our dataset is limited in its approximation of residence in a country exposed to armed conflict, as it does not capture the time path of locations that individuals may have lived between their birthplace and migration to the United States; (2) our dataset is limited in its lack of detail on the geographic location of origin within migrant sending countries in our study sample; (3) our dataset is limited in its lack of detail on the timing of migration by individuals in our study sample. More data collection is needed to understand the detailed migration history of individuals and their time path of residence in countries exposed to armed conflict; to ascertain, more precisely, the location of premigration residence within countries of origin and to measure the proximity of these location of premigration residence to armed conflicts; and to specify in more detail the timing of armed conflicts in days, weeks or months, rather than the more broad measures for years of premigration armed conflict and years since premigration armed conflict; (4) our dataset lacked information on other potentially relevant premigration variables such as premigration banditry, police abuse, and social disadvantage; and (5) our research to date was limited by its entirely quantitative focus. Munger et al. [3] show that much can be gleaned from qualitative data collection concerning specific experiences relating to food insecurity among immigrant populations concerning, for example, the ability to find and purchase culturally appropriate foods, and the availability of resources related to food insecurity and nutrition within local communities.

Although our research faces several technical limitations of existing datasets, we view these technical limitations as outweighed by the conceptual advances that we are able to contribute to literatures on armed conflict and food insecurity. In light of our findings, the existing literature on armed conflict and food insecurity is incomplete, as even studies that examine longer term effects of armed conflict ignore their effects on the food insecurity of displaced populations. These previously undocumented effects should be added to more typical analyses of the broad costs and consequences of political violence.

\section{CONFLICTS OF INTEREST}

The authors have no conflicts of interest to declare.

\section{ACKNOWLEDGMENTS}

All authors made substantial contributions to analyzing data, interpreting data, and critically revising the manuscript for important intellectual content. All authors approved the final version of the manuscript to be submitted. 


\section{Funding}

This research did not receive any specific grant from funding agencies in the public, commercial, or not-for-profit sectors.

\section{Ethical Approval}

Not required. The University Institutional Review Board determined that the research was not patient research, and was therefore exempt from further ethical review by the institution.

\section{REFERENCES}

[1] Torres-Aguilar P, Teran-Garcia M, Wiley A, Raffaelli M, Morales M. Factors correlated to protective and risk dietary patterns in immigrant Latino mothers in nonmetropolitan rural communities. J Immigr Minor Health 2016;18;652-59.

[2] Sano Y, Garasky S, Greder KA, Cook CC, Browder DE. Understanding food insecurity among Latino immigrant families in rural America. J Fam Econ Issues 2011;32;111-23.

[3] Munger AL, Lloyd TD, Speirs KE, Riera KC, Grutzmacher SK. More than just not enough: Experiences of food insecurity for Latino immigrants. J Immigr Minor Health 2015;17;1548-56.

[4] Arteaga I, Potochnick S, Parsons S. Decomposing the household food insecurity gap for children of US-born and foreign-born Hispanics: evidence from 1998 to 2011. J Immigr Minor Health 2017;19;1050-58.

[5] Dubowitz T, Acevedo-Garcia D, Salkeld J, Lindsay AC, Subramanian SV, Peterson KE. Lifecourse, immigrant status and acculturation in food purchasing and preparation among lowincome mothers. Public Health Nutr 2007;10;396-404.

[6] Quandt SA, Shoaf JI, Tapia J, Hernández-Pelletier M, Clark HM, Arcury TA. Experiences of Latino immigrant families in North Carolina help explain elevated levels of food insecurity and hunger. J Nutr 2006;136;2638-44.

[7] Chilton M, Black MM, Berkowitz C, Casey PH, Cook J, Cutts D, et al. Food insecurity and risk of poor health among US-born children of immigrants. Am J Public Health 2009;99;556-62.

[8] Moffat T, Mohammed C, Newbold KB. Cultural dimensions of food insecurity among immigrants and refugees. Hum Organ $2017 ; 76 ; 15-27$.

[9] Kaiser L, Baumrind N, Dumbauld S. Who is food-insecure in California? Findings from the California Women's Health Survey, 2004. Public Health Nutr 2007;10;574-81.

[10] Greenwald HP, Zajfen V. Food insecurity and food resource utilization in an urban immigrant community. J Immigr Minor Health 2017;19;179-86.

[11] Caspi CE, Tucker-Seeley RD, Adamkiewicz G, Roberto CA, Stoddard AM, Sorensen GC. Food hardship and obesity in a sample of low-income immigrants. J Immigr Minor Health 2017;19;130-37.

[12] Kamimura A, Jess A, Trinh HN, Aguilera G, Nourian MM, Assasnik N, et al. Food insecurity associated with self-efficacy and acculturation. Popul Health Manag 2017;20;66-73.

[13] Popovic-Lipovac A, Strasser B. A review on changes in food habits among immigrant women and implications for health. J Immigr Minor Health 2015;17;582-90.

[14] Maltz A. "Plant a victory garden: Our food is fighting:" Lessons of food resilience from World War. J Environ Stud Sci 2015;5;392-403.

[15] Messer E, Cohen MJ. Breaking the links between conflict and hunger redux. World Medical \& Health Policy 2015;7;211-33.

[16] Allouche J. The sustainability and resilience of global water and food systems: political analysis of the interplay between security, resource scarcity, political systems, and global trade. Food Policy 2011;36;S3-S8.

[17] Devakumar D, Birch M, Osrin D, Sondorp E, Wells JCK. The intergenerational effects of war on the health of children. BMC Med 2014;12;57.

[18] Leaning J, Guha-Sapir D. Natural disasters, armed conflict, and public health. N Engl J Med 2013;369;1836-42.

[19] Murray CJ, King G, Lopez AD, Tomijima N, Krug EG. Armed conflict as a public health problem. BMJ 2002;324;346-49.

[20] Koren O, Bagozzi BE. From global to local, food insecurity is associated with contemporary armed conflicts. Food Secur 2016;8;999-1010.

[21] Maxwell D, Russo L, Alinovi L. Constraints to addressing food insecurity in protracted crises. Proc Natl Acad Sci USA 2012;109;12321-25.

[22] Flood S, King M, Ruggles S, Warren JR. Integrated public use microdata series, current population survey: Version 4.0. 2015.

[23] Kilanowski JF, Lin L. Rasch analysis of US household food security survey module in Latino migrant farmworkers. J Hunger Environ Nutr 2012;7;178-91.

[24] Banna JC, Townsend, MS. Assessing factorial and convergent validity and reliability of a food behaviour checklist for Spanish-speaking participants in US Department of Agriculture nutrition education programmes. Public Health Nutr 2011;14;1165-76.

[25] Frongillo EA Jr. Validation of measures of food insecurity and hunger. J Nutr 1999;129;506S-9S.

[26] Center for Systemic Peace. Major episodes of political violence, 1946-2015. [Internet]. Integr Netw Soc Confl Res Data Page 2014. Available from: http://www.systemicpeace.org/inscrdata.html.

[27] Petersen T. A comment on presenting results from Logit and Probit models. Am Sociol Rev 1985;50;130-31.

[28] Mullahy J. Marginal effects in multivariate probit models. Empir Econ 2017;52;447-61.

[29] Dowd BE, Greene WH, Norton EC. Computation of standard errors. Health Serv Res 2014;49;731-50.

[30] StataCorp. Stata Statistical Software: Release 142015. 